\title{
Relative Bioavailability of Calcium from Calcium Formate, Calcium Citrate, and Calcium Carbonate
}

Publisher version available: $\underline{\text { http://ipet.aspetjournals.org/content/313/3/1217.full.pdf }}$

Author's accepted manuscript, available through PubMed Central:

http://ipet.aspetjournals.org/content/early/2005/02/25/ipet.104.081893

\section{Full Citation of published version:}

Hanzlik RP, Fowler SC, Fisher DH. Relative bioavailability of calcium from calcium formate, calcium citrate, and calcium carbonate. J Pharmacol Exp Ther. 2005 Jun; 313(3):1217-22.

\begin{abstract}
Calcium is an essential nutrient required in substantial amounts, but many diets are deficient in calcium making supplementation necessary or desirable. The objective of this study was to compare the oral bioavailability of calcium from calcium formate, a new experimental dietary calcium supplement, to that of calcium citrate and calcium carbonate. In a four-way crossover study, either a placebo or $1200 \mathrm{mg}$ of calcium as calcium carbonate, calcium citrate, or calcium formate were administered orally to 14 healthy adult female volunteers who had fasted overnight. After calcium carbonate, the maximum rise in serum calcium ( 4\%) and the fall in serum intact para-thyroid hormone 1-84 (iPTH) ( 20-40\%) did not differ significantly from placebo. After calcium citrate, the changes were modestly but significantly $(p<$ 0.05 ) greater, but only at 135 to 270 min after ingestion. In contrast, within 60 min after calcium formate serum calcium rose by approximately $15 \%$ and serum iPTH fell by $70 \%$. The mean increment in area under the plasma concentration-time curve (0-270 $\mathrm{min}$ ) for serum calcium after calcium formate (378 $\mathrm{mg} \cdot \mathrm{min} / \mathrm{dl}$ ) was double that for calcium citrate $(178 \mathrm{mg} \cdot \mathrm{min} / \mathrm{dl} ; \mathrm{p}<0.01)$, whereas the latter was only modestly greater than either placebo $(107 ; p<0.05)$ or calcium carbonate $(91 ; p<0.05)$. In this study, calcium formate was clearly superior to both calcium carbonate and calcium citrate in ability to deliver calcium to the bloodstream after oral administration. Calcium formate may offer significant advantages as a dietary calcium supplement.
\end{abstract}

Departments of Medicinal Chemistry (R.P.H.) and Pharmacology and Toxicology (S.C.F.), University of Kansas, Lawrence, Kansas; and AAI Development Services, Shawnee, Kansas (D.H.F.)

Accepted February 18, 2005 